\title{
The psychological burden of short stature: evidence against
}

\author{
Linda D Voss and David E Sandberg ${ }^{1,2}$ \\ Department of Endocrinology and Metabolism, Peninsula Medical School, Plymouth, UK, ${ }^{1}$ Departments of Psychiatry and Pediatrics, University of \\ Buffalo, The State University of New York and ${ }^{2}$ the Women and Children's Hospital of Buffalo, Buffalo, New York, USA
}

(Correspondence should be addressed to L D Voss, EarlyBird Research Centre, Child Health, Level 12, Derriford Hospital, Plymouth PL6 8DH, UK; Email: l.voss@phnt.swest.nhs.uk)

\begin{abstract}
Short stature, per se, is clearly not a disease, but is commonly perceived to be associated with social and psychological disadvantage. The assumption, widely held by pediatricians that short children are likely to be significantly affected by their stature, has been founded largely on older, poorly designed clinic-based studies and laboratory investigations of beliefs about the association between stature and individual characteristics. In contrast, data from more recent and better designed clinic- and community-based studies show that, in terms of psychosocial functioning, individuals with short stature are largely indistinguishable from their peers, whether in childhood, adolescence or adulthood. Parents and children alike should be reassured by these findings. In the absence of clear pathology, physical or psychological, GH therapy for the short but otherwise normal child raises ethical concerns about so-called 'cosmetic endocrinology'.
\end{abstract}

European Journal of Endocrinology 151 S29-S33

\section{Introduction}

Short stature (SS) may result from an idiopathic deficiency in growth hormone $(\mathrm{GH})$ or be a feature of a more complex syndrome or chronic disease, but it is usually found to be an isolated physical characteristic in an otherwise healthy child, i.e. 'idiopathic' or short normal stature (1).

Prior to the advent of biosynthetic or recombinant $\mathrm{GH}$ in 1985, limited supplies meant that only those children with classic GH deficiency (GHD) were considered for treatment. Since the introduction of $\mathrm{GH}$, the criteria for diagnosing GHD have become less stringent, but the identification of children most likely to benefit from treatment is still far from clear (2). First, biochemical tests for GHD are unreliable and secondly, the distribution of $\mathrm{GH}$ secretion appears to be continuous, tall children secreting more $\mathrm{GH}$ than short (3). Thus the notion of GH 'insufficiency' has arisen, leading, inevitably, to a somewhat grey area at the lower end of the continuum (4).

As a result, even short normal children are now considered potential targets for growth-promoting therapy. According to a recent report, some $40 \%$ of children on GH appear not to be GH deficient and, in the USA, idiopathic SS (ISS) alone accounts for about one-third of all children on GH $(5,6)$. Although there may be metabolic benefits of GH therapy in a few syndromes, such as Prader-Willi (7), the primary goal of treatment is usually an accelerated short-term growth rate and a greater final height. The rationale behind this goal is that SS constitutes a psychosocial burden (8). This belief is widespread. In a recent survey, $56 \%$ of physicians felt that height impaired emotional well-being in children below the 3rd centile (9). Thirty-two percent of these same physicians also believed that quality of life in non-GHD SS could be improved by an increase in height. There is little compelling evidence, however, for either.

\section{SS in the pediatric clinic}

It is the impression of many clinicians that individuals with marked SS are severely disadvantaged by their height (9-13). However, most studies dealing with the psychological adaptation of such children have been based on clinic referrals, including a variety of medical conditions (14). Many studies reported in the literature were conducted at a time when GH therapy was severely restricted and thus the patients involved tended to be those most severely affected by their condition.

Social problems reported in the clinic setting have included anxiety, introversion, stigmatization and juvenilization (14). Treating the child according to height age rather than chronological age may condition him or her to behave in a socially immature manner and to seek out younger children or adults (15). Alternatively, children with SS may be (or may be seen as) physically weaker than their peers, leading to parental overprotection, in itself a potent predictor of victimization by peers in the general school population $(16-19)$. At the other 
extreme, the short individual may try to overcompensate for SS by seeking peer approval as the group mascot or clown, or by being overly assertive and belligerent (20).

Most reports on short children's school performance have likewise been based on clinic-referred samples (21). Clinical syndromes featuring SS are often associated with academic underachievement, despite average intelligence, but are probably due to specific neurocognitive deficits associated with the particular syndrome (14). Importantly, in clinic-referred populations, academic achievement is largely unrelated to height and not remedied by GH therapy, even among those with well-recognized syndromes $(22,23)$. Nor, to date, have any short- or long-term psychological benefits of $\mathrm{GH}$ therapy been demonstrated in those with short normal stature (i.e. ISS) $(24,25)$.

It is sometimes assumed that delayed puberty, often associated with SS, will compound any psychological problems (26). It has even been suggested that the benefits of advancing puberty might outweigh the potential risk of attenuated adult height (27). The evidence, however, is inconclusive $(28-31)$. One follow-up study of constitutional growth delay revealed that many subjects remained unemployed and economically dependent on their parents as young adults, but that the level of educational attainment had not been seriously affected (32). Others have reported no significant psychological dysfunction in the adults traced (33-35).

More recent clinical research, avoiding many of the methodological flaws associated with earlier studies, is now questioning long-held beliefs regarding the presumed disability of SS $(21,36)$. Skuse et al. (37) reported no significant differences in peer acceptance, self-perception or social competence between clinicreferred children and their classmates. In a large, consecutively referred sample, Sandberg et al. (38) identified only minor difficulties of behavioural adaptation, mainly in boys. A Dutch study (39) reported similar findings in untreated young adults. Although threequarters reported a negative experience attributed to their SS, quality of life remained unimpaired.

\section{SS in the community}

Not all children with SS are referred for specialist evaluation. It would thus be a mistake to assume that the psychosocial or educational experiences of those who are referred will apply to the general population. Those seeking help are likely to have greater problems of psychosocial adaptation than those who do not. Parental perceptions are also potentially biased and any behavioural or emotional problems in the child may well be interpreted as stature related, even where this is not the case (4).

The Wessex Growth Study (40), a prospective cohort study, was unique for having recruited an unselected population of very short, but otherwise healthy children, from the age of 5 years (40). Children with known organic disease were excluded, the age range lay within a tight band, a wide range of socio-economic classes was represented, and the study incorporated case-matched controls of average stature. Results showed no evidence of serious psychosocial or academic disadvantage, before, during or, indeed, after puberty, in these youngsters (41-43). Although mean intelligence quotient (IQ) values between groups was significantly different this, again, was of no clinical import. Height, on its own, explained only $2 \%$ of the variance in IQ, emphasizing the need always to look beyond $P$ values and consider the effect size. The Wessex data merely confirmed other reports that socio-economic factors, rather than stature, best predict psychosocial and academic outcome $(44,45)$. As others have found, although short children would have preferred to be taller, and reported more bullying than taller peers, neither appeared to impact on school performance or self-esteem $(35,46)$. Such findings suggest that the stigmatized individual is able to call upon self-protective cognitive mechanisms that serve to leave the self-esteem intact (38). As Illich (47) has claimed, one aspect of good health is to be successful in coping with reality.

Two subsequent studies lend support to the Wessex data. Kranzler et al. (48) compared three groups of children: those referred with normal SS, a non-referred short group and case controls of average stature. The referred group appeared to have significantly more behavioural problems than the non-referred short group, which was indistinguishable from the averagestature control group. Busschbach et al. (49) compared adults with ISS, who had originally presented to a pediatric clinic, with equally short adults sampled from the population. The former clearly had poorer coping skills and claimed that the social disadvantages of SS dominated their social interactions. The latter showed no impairment in their quality of life. Thus it would seem that the discrepancy between earlier and more recent research can be explained by participant selection bias. These data strongly support the notion that behavioural and social difficulties are likely to be attributed to SS, even where these are largely unrelated (4). Parents and physicians alike can be reassured that, for most, SS is unlikely to be a burden, now or in the future $(50,51)$.

\section{Ethical considerations}

In the absence of clear pathology, physical or psychological, GH therapy for short but otherwise normal children raises issues as to the ethics of so-called 'cosmetic' or 'plastic endocrinology' $(52,53)$. Discussions range from whether such children deserve treatment, whether they should be entitled to treatment and 
whether SS is a medical or a social condition. At the heart of the controversy lies the fact that SS is neither life-threatening nor, in itself, a disease, in spite of attempts to demonstrate otherwise $(50,54,55)$.

One argument in support of GH therapy is based on the notion that medicine is primarily concerned with the relief of suffering, regardless of the aetiology of the condition (56). Why offer GH to the child who is $\mathrm{GH}$ deficient but not to another, who may be equally short, when one of the goals - to improve psychosocial functioning - might be the same (57)? According to this argument, the primary purpose of treatment is not to correct the cause but to mitigate the handicap or disability of SS (58), but this presupposes that SS does indeed lead to suffering or, at the very least, social disadvantage.

Even if it could be established that the short adult is at a social disadvantage, it is debatable whether the role of medicine is to make everyone equal competitors in life (59). There are further issues for parents to consider. Commercial pressures play a significant role, not least whenever investigators are funded to discover new indications for a drug (60). Indeed, the cynic might argue that shortness became a disease only when a treatment became available (55). Routine growth screening may be of value if it facilitates the detection of previously undetected pathology, although most short children thus identified will have no obvious pathology (61). Care must be taken to reassure them that they are indeed healthy and normal. There is a danger that demands for treatment may be motivated less by concern for the children than by the aspirations of their parents who may wish to give their children a perceived advantage in life (62). They should bear in mind, however, that where the SS is familial, treatment will not prevent SS from recurring in subsequent generations.

Any attempt by the parent to modify their child's appearance may signal tacit disapproval and a concern that they are unacceptable as they are (63). There is also a danger that the short child who has unrealistic expectations as to the benefits of treatment may be frustrated and disappointed by what is perceived as 'treatment failure' (64). The outcome of GH treatment, where there is no GHD, is neither predictable nor very dramatic in terms of centimetres gained $(65,66)$. A further consideration is the long-term safety of recombinant human GH, yet to be established (67).

Finally, there is an argument for not spending limited resources on so-called 'cosmetic endocrinology' when there may be cheaper, non-invasive options $(68,69)$.

As Brook (70) suggests, it is much more important for a short child to acquire coping skills than to buy inches through pharmacological means. The widespread use of $\mathrm{GH}$, as a first line of treatment, risks perpetuating a climate of opinion where SS is unacceptable, both to parents and society, and is likely to lead to a spiralling demand for therapy.

\section{References}

1 Ranke MB. Towards a consensus on the definition of idiopathic short stature. Hormone Research 199645 (Suppl 2) 64-66.

2 Guyda HJ. Four decades of growth hormone therapy for short children: what have we achieved? Journal of Clinical Endocrinology and Metabolism $1999 \mathbf{8 4} 4307-4316$.

3 Hindmarsh P, Smith P, Brook C \& Matthews D. The relationship between height velocity and 24 hour growth hormone secretion in children. Clinical Endocrinology 198727 581-591.

4 Sandberg DE \& Voss LD. The psychosocial consequences of short stature: a review of the evidence. Best Practice and Research Clinical Endocrinology and Metabolism 200216 449-463.

5 KIGS International Board/Pharmacia Corporation. Pharmacia International Growth Database, Report no. 18. Biannual Report. Stockholm, 2001.

6 Vance ML \& Mauras N. Growth hormone therapy in adults and children. New England Journal of Medicine 1999341 1206-1216.

7 Lee PDK, Allen DB, Angulo MA et al. Consensus statement Prader-Willi syndrome: growth hormone (GH)/insulin-like growth factor axis deficiency and $\mathrm{GH}$ treatment. Endocrinologist 200010 (Suppl 1) 71S-73S.

8 Sandberg DE. Should short children who are not deficient in growth hormone be treated? Western Journal of Medicine 2000 172 186-189.

9 Cuttler L, Silvers JB, Singh J, Marrero U, Finkelstein B, Tannin G \& Neuhauser D. Short stature and growth hormone therapy. A national study of physician recommended patterns. Journal of the American Medical Association 1996276 531-537.

10 Stabler B \& Gilbert MC. Psychological effects of growth delay. In Growth Abnormalities, pp 255-274. Eds R Hintz \& R Rosenfeld. New York: Churchill Livingstone, 1987.

11 Lee PDK \& Rosenfeld RG. Psychosocial correlates of short stature and delayed puberty. Pediatric Clinics of North America 198734 $851-863$.

12 Underwood LE. The social cost of being short: societal perceptions and biases. Acta Paediatrica Scandinavica 1991377 (Suppl) 3-8.

13 Stabler B, Siegel PT, Clopper RR, Stoppiani CE, Compton PG \& Underwood LE. Behaviour change after growth hormone treatment of children with short stature. Journal of Pediatrics 1998 $133366-373$.

14 Sandberg DE. Short stature: intellectual and behavioral aspects. In Pediatric Endocrinology, edn 3, pp 149-162. Ed F Lifshitz. New York: Marcel Dekker, 1996.

15 Lerner RM \& Gellert E. Body build identification, preference and aversion in children. Developmental Psychology 19691 456-462.

16 Kusalic M, Fortin C \& Gauthier Y. Psychodynamic aspects of dwarfism. Response to growth hormone treatment. Canadian Psychiatric Association Journal 197217 29-34.

17 Rotnem D, Genel M, Hintz RL \& Cohen DJ. Personality development in children with growth hormone deficiency. Journal of the American Academy of Child Psychiatry 197716 412-426.

18 Holmes CS, Hayford JT \& Thompson RG. Parents' and teachers' differing views of short children's behaviour. Child Care, Health and Development $1982 \mathbf{8} 327-336$.

19 Olweus D. Bully/victim problems among school children: basic facts and effects of a school based intervention program. In The Development and Treatment of Childhood Aggression, pp 411-448. Eds DJ Pepler \& KH Rubin. Hillsdale, NJ: Lawrence Erlbaum Associates, 1991.

20 Meyer-Bahlburg HFL. Short stature: psychological issues. In Pediatric Endocrinology. A Clinical Guide, edn 2, pp 173-196. Ed F Lifshitz. New York: Marcel Dekker, 1990.

21 Voss LD \& Mulligan J. The short 'normal' child in school: selfesteem, behaviour and attainment before puberty (The Wessex Growth Study). In Growth, Stature and Adaptation, pp 47-64. Eds B Stabler \& LE Underwood. Chapel Hill, NC: University of North Carolina at Chapel Hill Press, 1994.

22 Sandberg DE, MacGillivray MH, Clopper RR, Fung C, LeRoux L \& Alliger DE. Quality of life (QOL) among formerly treated 
child-onset growth hormone-deficient (GHD) adults: a comparison with unaffected siblings. Journal of Clinical Endocrinology and Metabolism $1998 \mathbf{8 3} 1134-1142$.

23 Lagrou K, Xhrouet-Heinrichs D, Heinrichs C, Craen M, Chanoine JP, Malvaux P \& Bourguignon JP. Age-related perception of stature, acceptance of therapy, and psychosocial functioning in human growth hormone-treated girls with Turner's syndrome. Journal of Clinical Endocrinology and Metabolism $1998 \mathbf{8 3}$ 1494-1501.

24 Theunissen NC, Kamp GA, Koopman HM, Zwinderman KA, Vogels T \& Wit JM. Quality of life and self-esteem in children treated for idiopathic short stature. Journal of Pediatrics 2002140 $507-515$

25 Pasquino AM, Albanese A, Bozzola M, Butler GE, Buzi F, Cherubini V, Chiarelli F, Cavallo L, Drop SL, Stanhope R \& Kelnar CJ. Idiopathic short stature. Journal of Pediatric Endocrinology and Metabolism 200114 (Suppl 2) 967-974.

26 Drash PW. Psychologic counselling in dwarfism. In Endocrine and Genetic Diseases of Childhood, pp 1014-1022. Ed LI Gardner. Philadelphia: WB Saunders, 1969.

27 Gordon M, Crouthamel C, Post EM \& Richman RA. Psychosocial aspects of constitutional short stature: social competence, behavior problems, self-esteem and family functioning. Journal of Pediatrics $1982 \mathbf{1 0 1} 477-480$.

28 Zimet GD, Cutler M, Litvene M, Dahms W, Owens R \& Cuttler L. Psychological adjustment of children evaluated for short stature: a preliminary report. Journal of Developmental and Behavioral Pediatrics $199516264-270$.

29 Apter A, Galatzer A, Beth-Halachmi N \& Laron Z. Self-image in adolescents with delayed puberty and growth retardation. Journal of Youth and Adolescence $1981 \mathbf{1 0} 501-505$.

30 Lewis VG, Money J \& Bobrow NA. Idiopathic pubertal delay beyond age fifteen: psychologic study of twelve boys. Adolescence $1977121-11$.

31 Holmes CS, Karlsson JA \& Thompson RB. Social and school competencies in children with short stature. Longitudinal patterns. Journal of Developmental and Behavioral Paediatrics 19856 263-267.

32 Sartorio A, Morabito F, Peri G, Conti A \& Faglia G. The social outcome of adults with constitutional growth delay. Journal of Endocrinological Investigation 199013 593-595.

33 Zimet G, Cutler M \& Owens R. Psychosocial functioning of adults who were short as children. In Growth, Stature and Adaptation, pp 73-82. Eds B Stabler \& LE Underwood. Chaple Hill, NC: University of North Carolina at Chapel Hill Press, 1994.

34 Crowne EC, Shalet SM, Wallace WHB, Eminson DM \& Price DA. Final height in boys with untreated constitutional delay in growth and puberty. Archives of Diseases in Childhood 199065 1109-1112.

35 Crowne EC, Shalet SM, Wallace WHB, Eminson DM \& Price DA. Final height in girls with untreated constitutional delay of growth and puberty. European Journal of Pediatrics $1991 \mathbf{1 5 0}$ $708-712$.

36 Sandberg DE, Kranzler J, Bukowski WM \& Rosenbloom AL. Psychosocial aspects of short stature and growth hormone therapy. Journal of Pediatrics 1999135 133-134.

37 Skuse D, Gilmour J, Tian CS \& Hindmarsh P. Psychosocial assessment of children with short stature a preliminary report. Acta Paediatrica Scandinavica 1994406 (Suppl) 11-16.

38 Sandberg DE, Brook AE \& Campos SP. Short stature: a psychosocial burden requiring growth hormone therapy. Pediatrics 1994 $94832-840$.

39 Rekers-Mombarg LTM, Busschbach JJV, Massa GG, Dicke J \& Wit JM. Quality of life of young adults with idiopathic short stature: effect of growth hormone treatment. Acta Paediatrica $1998 \mathbf{8 7}$ 865-870.

40 Voss LD, Walker JM, Lunt H, Wilkin T \& Betts P. The Wessex Growth Study First report. Acta Paediatrica Scandinavica 1989 349 (Suppl) $65-72$.
41 Voss LD. Short stature and school performance. Acta Paediatrica Scandinavica 1991337 (Suppl) 29-31.

42 Downie AB, Mulligan J, Stratford RJ, Betts PR \& Voss LD. Are short normal children at a disadvantage? British Medical Journal 1997 314 97-100.

43 Ulph F, Betts P, Mulligan J \& Stratford RJ. Personality functioning: the influence of stature. Archives of Diseases in Childhood $2004 \mathbf{8 9}$ $17-21$.

44 Wilson DM, Hammer LD, Duncan PM, Dornbusch SM, Ritter PL, Hintz RL, Gross GT \& Rosenfeld RG. Growth and intellectual development. Pediatrics $1986 \mathbf{7 8} 646-650$.

45 Vance MD, Ingersoll GM \& Golden MP. Short stature in a non-clinical sample: not a big problem. In Growth, Stature and Adaptation, pp 35-45. Eds B Stabler \& LE Underwood. Chapel Hill, NC: University of North Carolina at Chapel Hill Press, 1994.

46 Voss LD \& Mulligan J. Bullying in school: are short children at risk. British Medical Journal $2000320612-613$.

47 Illich I. Limits to Medicine. London, UK: Penguin Books, 1996.

48 Kranzler JH, Rosenbloom AL, Proctor B, Diamond FB Jr \& Watson M. Is short stature a handicap? A comparison of the psychosocial functioning of referred and non-referred children with normal short stature and children with normal stature. Journal of Pediatrics 2000136 96-102.

49 Busschbach JJV, Rikken B, Grobbee DE, de Charro FT \& Wit JM. Quality of life in short adults. Hormone Research $1998 \mathbf{4 9 0}$ $32-38$.

50 Voss LD. Short but normal. Archives of Diseases in Childhood 1999 $81370-371$.

51 Voss LD. Short normal stature and psychosocial disadvantage: a critical review of the evidence. Journal of Pediatric Endocrinology and Metabolism 200114 701-711.

52 Allen DB, Brook CGD, Bridges NA, Hindmarsh PC, Guyda HJ \& Frazier D. Therapeutic controversies: growth hormone treatment on non-GH deficient subjects. Journal of Clinical Endocrinology and Metabolism 199479 1239-1248.

53 Tanner JM. The two faces of human auxology: therapy of individuals and monitoring of populations. Acta Medica Auxologica 1993 $2571-74$.

54 Voss LD \& Mulligan J. Normal growth in the short normal prepubertal child: the Wessex Growth Study. Journal of Medical Screening $19985127-130$.

55 Voss LD. Growth hormone therapy for the short normal child: who needs it and who wants it? Journal of Pediatrics 2000136 $103-110$.

56 Churchill LR. Bias, opportunity and justice in growth hormone therapy. In Growth, Stature and Adaptation, pp 195-202. Eds B Stabler \& LE Underwood. Chapel Hill, NC: University of North Carolina at Chapel Hill Press, 1994.

57 Neely EK \& Rosenfeld RG. Use and abuse of human growth hormone. Annual Review of Medicine 199445 407-420.

58 Fost N. Is the treatment/enhancement distinction useful? Endocrinologist 200111 (Suppl 1) 72S-77S.

59 Daniels N. Growth hormone therapy for short stature: can we support the treatment/enhancement distinction? Growth, Genetics and Hormones 19928 (Suppl 1) 46-48.

60 Lantos JD. Ethics and growth hormone: where have we been and where are we going? In Growth, Stature and Adaptation, pp 213-219. Eds B Stabler \& LE Underwood. Chapel Hill, NC: University of North Carolina at Chapel Hill Press, 1994.

61 Voss LD, Mulligan J, Betts PR \& Wilkin TJ. Poor growth in school entrants as an index of organic disease. British Medical Journal 1992305 1400-1402.

62 Underwood LE \& Rieser PA. Is it ethical to treat healthy short children with growth hormone? Acta Paediatrica Scandinavica 1989 362 (Suppl) 18-23.

63 Diekema DS. Is taller really better? Growth hormone therapy in short children. Perspectives in Biology and Medicine 199034 $109-123$ 
64 Rotnem D, Cohen D, Hintz R \& Genel M. Psychological sequelae of relative 'treatment failure' for children receiving GH replacement. Journal of the American Academy of Child Psychiatry 197918 $505-520$

65 Hintz RL, Attie KM, Baptista J \& Roche A. Effect of growth hormone treatment on adult height of children with idiopathic short stature. New England Journal of Medicine 1999340 $502-507$.

66 Finkelstein BS, Imperiale TF, Speroff T, Marrero U, Radcliffe DJ \& Cuttler L. Effect of growth hormone therapy on height in children with idiopathic short stature: a meta-analysis. Archives of Pediatric and Adolescent Medicine $2002156230-240$.

67 Clayton PE \& Cowell CT. Safety issues in children and adolescents during growth hormone therapy - a review. Growth Hormone and IGF Research $200010306-317$.
68 Guyda HJ. Growth hormone therapy for non-growth hormone deficient children with short stature. Current Opinion in Pediatrics $199810416-421$.

69 Eminson M, Powell RP \& Hollis S. Cognitive behaviour interventions with short statured boys: a pilot study. In Growth, Stature and Adaptation, pp 135-150. Eds B Stabler \& LE Underwood. Chapel Hill, NC: University of North Carolina at Chapel Hill Press, 1994.

70 Brook CGD. Growth hormone: panacea or punishment for short stature? British Medical Journal $1997315692-693$.

Received 28 January 2004

Accepted 3 May 2004 